\title{
Conversion of oil palm trunk into bio-oil via treatment with subcritical water
}

\begin{abstract}
Subcritical water was applied to produce bio-oil from a 21-year-old abandoned oil palm trunk (OPT). The effects of reaction temperature, time, part of trunk taken, and optimum reaction condition were investigated. Higher heating values (HHVs), CHNS/O elemental and GC-MS analysis were performed to characterize the bio-oil. The subcritical water temperatures were manipulated between $100{ }^{\circ} \mathrm{C}$ and $370{ }^{\circ} \mathrm{C}$ with $10^{\circ} \mathrm{C}$ intervals and the reaction time was varied between $6 \mathrm{~s}$ and $20 \mathrm{~min}$. The maximum yield of bio-oil from subcritical water treatment of top and bottom part of OPT was 0.27 and $0.30 \mathrm{~kg} / \mathrm{kg}$-dry OPT, respectively. The optimum reaction time and temperature was $5 \mathrm{~min}$ and $330^{\circ} \mathrm{C}$. The highest $\mathrm{HHV}$ of the bio-oils derived from the top and bottom part of OPT was $33.2 \mathrm{MJ} / \mathrm{kg}$ and $26.4 \mathrm{MJ} / \mathrm{kg}$, respectively. From GC-MS measurement, the bio-oil contained phenolic compounds. The bio-oil derived from OPT obtained from subcritical water treatment had high HHV and comparable to other liquid fuels.
\end{abstract}

Keyword: Subcritical water treatment; Oil palm trunk; Bio-oil; Heating value 